\title{
Safety and effectiveness of a novel generator algorithm for bipolar vessel sealing: a randomised controlled chronic animal study
}

Bernhard Kraemer', Christos Tsaousidis ${ }^{1}$, Stephan Kruck², Martin Schenk', Marcus Scharpf ${ }^{1}$, Stefan Kommoss ${ }^{1}$, Sara Brucker ${ }^{1}$, Daniela Nuessle ${ }^{3}$, Markus D. Enderle ${ }^{3}$ and Ulrich Biber ${ }^{3^{*}}$ (i)

\begin{abstract}
Background: Electrosurgical vessel sealers are gradually replacing conventional techniques such as ligation and clipping. Algorithms that control electrosurgical units (ESU), known as modes, are important for applications in different surgical disciplines. This chronic porcine animal study aimed to evaluate the safety and effectiveness of the novel thermoSEAL electrosurgical vessel sealing mode (TSM). The BiClamp ${ }^{\oplus}$ mode (BCM) of the renowned $\mathrm{VIO}^{\circledR} 300$ D ESU served as control. BCM has been widely available since 2002 and has since been successfully used in many surgical disciplines. The TSM, for the novel $\mathrm{VIO}^{\oplus} 3 \mathrm{ESU}$, was developed to reduce sealing time and/or thermal lateral spread adjacent to the seal while maintaining clinical success rates. The primary aim of this study was to investigate the long-term and intraoperative seal quality of TSM.
\end{abstract}

Methods: The BiCision ${ }^{\oplus}$ device was used for vessel sealing with TSM and BCM in ten German Landrace pigs which underwent splenectomy and unilateral nephrectomy during the first intervention of the study. The seals were cut with the BiCision ${ }^{\circledast}$ knife. Ninety-nine arteries, veins and vascular bundles were chronically sealed for 5 or 21 days. Thereafter, during the second and terminal intervention of the study, 97 additional arteries and veins were sealed. The carotid arteries were used for histological evaluation of thermal spread.

Results: After each survival period, no long-term complications occurred with either mode. The intraoperative seal failure rates, i.e. vessel leaking or residual blood flow after the first sealing activation, were $2 \%$ with TSM versus $6 \%$ with BCM $(p=0.28)$. The sealing time was significantly shorter with TSM ( $3.5 \pm 0.69 \mathrm{~s}$ vs. $7.3 \pm 1.3 \mathrm{~s}, p<0.0001)$. The thermal spread and burst pressure of arteries sealed with both modes were similar $(p=0.18$ and $p=0.61)$ and corresponded to the histological evaluation. The measured tissue sticking parameter was rare with both modes ( $p=0.33$ ). Tissue charring did not occur. Regarding the cut quality, $97 \%$ of the seals were severed in the first and $3 \%$ in the second attempt (both with TSM and BCM).

Conclusions: The novel TSM seals blood vessels twice as fast as the BCM while maintaining excellent tissue effect and clinical success rates.

Trial registration: Not applicable.

Keywords: Swine, Animal model, Burst pressure, Thermal damage, Sealing time, Algorithm

\footnotetext{
* Correspondence: ulrich.biber@erbe-med.com

${ }^{3}$ Erbe Elektromedizin GmbH, Waldhoernlestrasse 17, 72072 Tuebingen,

Germany

Full list of author information is available at the end of the article
}

(c) The Author(s). 2019 Open Access This article is distributed under the terms of the Creative Commons Attribution 4.0 International License (http://creativecommons.org/licenses/by/4.0/), which permits unrestricted use, distribution, and reproduction in any medium, provided you give appropriate credit to the original author(s) and the source, provide a link to the Creative Commons license, and indicate if changes were made. The Creative Commons Public Domain Dedication waiver (http://creativecommons.org/publicdomain/zero/1.0/) applies to the data made available in this article, unless otherwise stated. 


\section{Background}

Bipolar electrosurgical devices are becoming increasingly important for vessel sealing. These devices are gradually replacing conventional techniques such as ligation and clipping, especially in laparoscopic surgery. In addition to pure vessel sealers, there are also devices that not only seal vessels up to a diameter of $7 \mathrm{~mm}$, but can also cut through the coagulated tissue [1-3], e. g. BiCision ${ }^{\bullet}$, EnSeal $^{\oplus}$ or LigaSure ${ }^{\oplus}$. Besides geometry, materials and design of the devices where tissue contact occurs, the modes, i.e. tailor-made 'ESU algorithms', are particularly important for the respective application. In order to achieve an optimal interaction between ESU, device and tissue, special modes were developed and optimized with regard to the electrical parameters. One such new tissue-sparing mode for vessel sealing called "thermoSEAL mode" (TSM) was specially developed for the novel $\mathrm{VIO}^{\circ} 3 \mathrm{ESU}$ (Erbe Elektromedizin $\mathrm{GmbH}$, Tuebingen, Germany). The mode permanently monitors the electrical tissue properties and offers an optimized setting for sealing different tissue types. Ideally, the sealing time and thermal lateral spread (TL) adjacent to the site of electrothermal fusion should be reduced compared to the clinically established pulsed BCM (automatically modulated sine-wave signal form with a fundamental frequency of $350 \mathrm{kHz}$ as previously described [4]) of the well-known $\mathrm{VIO}^{\circ} 300 \mathrm{D}$ ESU, which has been successfully used for many years [4-6]. Previous ex vivo laboratory tests, in which post mortem tissue of explanted porcine renal arteries was sealed with TSM and BCM, as well as first in vivo porcine animal tests show that the TSM should be safe and effective in this sense [7].

A wide range of citations in peer reviewed scientific literature shows that the porcine model is established for preclinical studies during the development of thermosurgical devices [2, 8-24]. The primary aim of this study was the safety evaluation of the TSM in terms of survival, long-term seal quality and intraoperative seal failure rate in a survival porcine animal model. The secondary aim was to evaluate the effectiveness associated with the use of the TSM and thus burst pressure (BP), TL, sealing time, tissue sticking to the device and charring of tissue were assessed.

\section{Methods}

\section{Experimental animals}

This study was reviewed and approved by the institutional review board for animal experiments, Regierungspraesidium Tuebingen, Germany (Approval No. F2/15) in compliance with the Animals Scientific Procedures Act 1986. Ten female German Landrace pigs aged approximately 12 weeks with a mean body weight of $41.3 \pm 4.83 \mathrm{~kg}$ were used. The animals were obtained from a commercial pig breeder in Baden-Wuerttemberg,
Germany and kept on straw in cages of $6.24 \mathrm{~m}^{2}(1-3$ animals per cage) at a temperature of approximately $20^{\circ} \mathrm{C}$ and a relative humidity of approximately $60 \%$ with natural illumination and tap water ad libitum. After a 7-day adaptation period, the pigs were starved in the morning before the surgical intervention. During the 5-day and 21-day survival period, the animals were housed as described above and clinically examined at least once a day by the veterinarian. All deviations from the expected course (e. g. refusal to eat, reduced mobility) were recorded, discussed and treated. In addition, the animals were evaluated by a scoring system that assessed the sensory awareness, food and water intake (appetence) and mobility behaviour.

\section{Premedication and anaesthesia}

Before each surgical intervention, intramuscular premedication was performed using atropine $(0.05 \mathrm{mg} / \mathrm{kg}$, Dr. Franz Koehler Chemie GmbH Bensheim, Germany), azaperone $(4.0 \mathrm{mg} / \mathrm{kg}$, Elanco Animal Health, Bad Homburg, Germany), ketamine $(14.0 \mathrm{mg} / \mathrm{kg}$, Serumwerke Bernburg AG, Germany) and midazolam $(1.0 \mathrm{mg} / \mathrm{kg}$, ratiopharm $\mathrm{GmbH}$, Ulm, Germany). A bolus of 2.0-5.0 $\mathrm{mg} / \mathrm{kg}$ propofol (Fresenius Kabi, Bad Homburg, Germany) was administered intravenously prior to tracheal intubation. During the operation the animals were monitored, ventilated and kept in deep anaesthesia with $1.8 \%$ isoflurane (CP-Pharma Handelsgesellschaft $\mathrm{mbH}$, Burgdorf, Germany) and fentanyl (ratiopharm $\mathrm{GmbH}$, Ulm, Germany) at an intravenous dose of $30-100 \mu \mathrm{g} / \mathrm{kg} /$ h. Finally, the animals were euthanized with an intravenous injection of $\mathrm{T} 61$ (Intervet Deutschland $\mathrm{GmbH}$, Germany).

\section{Surgical procedure}

Experienced surgeons (two gynaecologists and one urologist) with corresponding expertise in animal tests performed the surgical interventions. In the primary experiment (first intervention of the study), a midline laparotomy was performed, followed by splenectomy and unilateral nephrectomy according to the randomization (left or right). Incisions were made in both groins to locate the saphenous vessels. Splenic and renal arteries, veins and vascular bundles (combination of arteries and/or veins and connective tissue) as well as both saphenous arteries were compressed with a calibrated force and sealed with the BiCision ${ }^{\circledR}$ device. The Autostop function ended the activation. To aid location after nephrectomy and splenectomy and on second look, the seals were marked distally with fine sutures immediately after sealing without affecting the proximal sealing zone. The seals were severed with the cut function (knife) of the BiCision ${ }^{\odot}$ with the exception of the saphenous arteries. All seals were thoroughly checked for 
leakage by macroscopic inspection before the abdomen and groin were closed. In the terminal experiment (second and terminal intervention of the study), after a survival period of either 5 or 21 days ( 5 animals per survival period), relaparotomy was performed and further blood vessels were sealed: the remaining contralateral renal arteries and veins, one of the carotid arteries, both axillary and femoral arteries and both jugular veins. After $2 \mathrm{~h}$ of prolonged survival period, these vessels were excised. Finally, the pigs were euthanized.

\section{Experimental design}

This was a controlled, randomised, prospective and chronic animal study stratified by survival period ( 5 or 21 days). Five animals were used per survival period. The number of animals was selected to comply with FDA guidance "Premarket Notification (510(k)) Submissions for Bipolar Electrosurgical Vessel Sealers for General Surgery". The bipolar vessel sealer BiCision ${ }^{\circ}$ was used in combination with each of the following modes: in the test group blood vessels were sealed with the novel TSM, while in the control group the BCM was used. The blood vessels sealed in each animal were randomised to the test and the control group to minimise subjective bias. The TSM was operated by a $\mathrm{VIO}^{\circ} 3 \mathrm{ESU}$ (Erbe Elektromedizin GmbH, Tuebingen, Germany) with the setting Effect 1 . The $\mathrm{BCM}$ was driven by a $\mathrm{VIO}^{\circ} 300$ D ESU (Erbe Elektromedizin GmbH, Tuebingen, Germany) with Effect 2. Both were the default setting for the BiCision ${ }^{\circ}$ device of the respective ESU. At least ten vessels per mode and survival period should be sealed chronically for the evaluation of long-term seal quality. An estimated 45 arteries and veins per mode should be sealed in the terminal experiments and used for the ex vivo evaluation of TL and BP. The carotid arteries were sent in for histological evaluation of TL.

\section{Vessel diameter}

The vessel diameter was determined in situ immediately before each sealing procedure using a calliper gauge and documented in both the primary and terminal experiments.

\section{Survival rate, long-term seal quality and intraoperative seal failure (primary aim)}

A good state of health with positive weight development, as monitored by the veterinarian during the survival period, was documented as successful survival. Longterm seal quality was documented for vessels sealed during the primary experiment and was evaluated during the terminal experiment, including signs of complications or signs of bleeding or damage to the sealing site or to surrounding tissue macroscopically assessed for adjacent blood clots or minor hematomas. Intraoperative seal failure was documented in both the primary and terminal experiments. The definition of intraoperative seal failure was that the surgeon detected vessel leaking or residual blood flow immediately after the first sealing activation. In the event of such a failure, a maximum of two further activations were made to electrothermally seal the vessel. If this was not successful, the vessel was sutured.

\section{Sealing time}

The sealing time (a secondary aim) was documented in both the primary and terminal experiments.

\section{Thermal lateral spread (TL) and burst pressure (BP)}

The TL (a secondary aim) of the blood vessel specimens was obtained microscopically ex vivo by measuring the extent of the coagulation necrosis from the edge of the seal to the edge of the whitish discoloration of the tissue by coagulation. The sealed section of each vessel was then severed and both vascular stumps were subjected to ex vivo BP testing (a secondary aim). Physiological saline solution was instilled using a tailor-made, semiautomated BP test setup with continuous pressure monitoring. The pressure was increased until the fusion area leaked or burst. The maximum pressure was recorded as the $\mathrm{BP}$ value for each vascular stump. TL and BP were only documented for tissue samples from the terminal experiments ( $2 \mathrm{~h}$ survival period).

\section{Tissue sticking, tissue charring and cut quality}

The tissue sticking to the device and charring of coagulated tissue (both secondary aims) were evaluated by the surgeon after each sealing procedure: $0=$ "no sticking", $1=$ "sticking, but easy to remove the device", 2 = "sticking and difficult to remove the device", $3=$ "sticking and difficult to remove the device and seal damaged" and $0=$ "no charring", $1=$ "moderate charring", $2=$ "intense charring". The cut quality was derived from the number of cut attempts per seal. These parameters were documented in both the primary and terminal experiments.

\section{Histological evaluation}

During the terminal experiments, sealed carotid arteries with a 2-h survival period were excised, pinned on cork and fixed in $4.5 \%$ phosphate buffered formalin. They were cut longitudinally, embedded in paraffin and cut into $3 \mu \mathrm{m}$ sections which were stained with haematoxylin and eosin (HE), Masson's trichrome (MTC) and Picro Sirius Red (PSR) stain. The HE stain was used to obtain a histological overview. The MTC stain is a special staining technique that distinguishes the muscle from connective tissue and is particularly advantageous because the thermal damage zone with denatured protein/collagen has a bright red colour. For confirmation, 
PSR was additionally performed and viewed under the polarizing microscope. The PSR stain is intended for use in the histological visualization of collagen and muscle fibres in tissue sections. It is viewed using standard light microscopy or polarized light, which results in birefringence of intact collagen fibres and denatured tissue appears as non-birefringent.

\section{Statistical analysis}

The statistical evaluation was done with GraphPad Prism (Version 7.01, U.S.A.). Since no considerable differences were observed between the group of all ten animals and the two groups of five animals per survival period, only the group of all ten animals was considered in the results section. Descriptive statistics (mean and standard deviation) were performed to describe the basic characteristics of the collected data. Fisher's exact test was implemented to determine differences between two groups of categorical data (intraoperative seal failure, tissue sticking and charring) and the chi-squared test to determine differences between more than two groups. Differences between two groups of independent quantitative data (vessel diameter, sealing time, TL, $\mathrm{BP}$, cut quality) were detected using a unpaired, two-tailed Student's T-test provided the data were normally distributed, as confirmed by a Kolmogorov-Smirnov-Test. Otherwise, the Mann-Whitney test was performed. The equality of variance between two groups was checked with the Ftest. Differences between independent quantitative data of more than two groups were determined by a one-way analysis of variance (ANOVA), provided that the data was normally distributed. If non-normal distribution was found for one of the groups, a Kruskal-Wallis test was used. $P$-values $<0.05$ were considered significant.

\section{Results}

\section{Vessel diameter}

A total of 196 seals were performed during the primary and the terminal experiments, including 112 arteries, 66 veins and 18 vascular bundles. The mean vessel diameters did not differ between the two modes $(p>0.05)$, which was also true for certain vessel types (Table 1). In the primary experiment, 99 vessel seals (TSM: 50, BCM: 49) were performed. Among them were 48 arteries (TSM: 25, BCM: 23), 33 veins (TSM: 19, BCM: 14) and 18 vascular bundles (TSM: $6, \mathrm{BCM}: 12$ ). The mean vessel diameters did not differ between the two modes (Table 2). In the terminal experiment, 97 vessel seals (TSM: 48, BCM: 49) were performed. Among them were 64 arteries (TSM: 31, BCM: 33 ) and 33 veins (TSM: 17, BCM: 16). The mean vessel diameters did not differ between the two modes (Table 3).

\section{Survival rate}

There were no adverse events and none of the animals $(0 / 10)$ died after the primary experiment or during the survival periods. In all animals (10/10), seroma formation could be observed postoperatively at the surgical site in the groin area, which did not lead to any clinically relevant impairment. Apart from this, there were no postoperative anomalies. This was in line with the weight gain of the animals (10/10), which corresponded to the weight gain observed in healthy pigs fed on a needs-based, non-compulsory diet. Apart from postoperative analgesia and prophylactic antibiotics, no further veterinary interventions were necessary.

\section{Long-term seal quality}

A total of 99 vessel sealings (TSM: 50, BCM: 49) with similar mean vessel diameters (TSM: $4.5 \mathrm{~mm}$, BCM: 4.4 $\mathrm{mm}$, Table 2) and diameter ranges (TSM: 2.1-9.6 mm, BCM: 2.2-9.0 mm, Table 2) for both modes were assessed for long-term seal quality. There was no difference between TSM and BCM, i.e. the clinical success rate was $100 \%$ for both modes. On relaparotomy after 5 days, the sealing sites and the surrounding tissue did not show any signs of complications or evidence of bleeding.

Table 1 In situ vessel or vascular bundle diameters immediately before sealing (All vessels)

\begin{tabular}{|c|c|c|c|c|c|}
\hline \multirow[t]{2}{*}{ Vessel type } & \multicolumn{2}{|c|}{ thermoSEAL mode (TSM) } & \multicolumn{2}{|c|}{ BiClamp $^{\oplus}$ mode (BCM) } & \multirow[t]{2}{*}{$p$ value } \\
\hline & No. & mean \pm STD (range) $[\mathrm{mm}]$ & No. & mean \pm STD (range) $[\mathrm{mm}]$ & \\
\hline All vessels & 98 & $4.4 \pm 1.4(2.1-9.6)$ & 98 & $4.3 \pm 1.4(2.0-11)$ & 0.65 \\
\hline Arteries & 56 & $4.0 \pm 0.9(2.1-6.0)$ & 56 & $4.1 \pm 1.0(2.5-6.8)$ & 0.83 \\
\hline Veins & 36 & $5.0 \pm 1.9(2.1-9.6)$ & 30 & $4.7 \pm 1.9(2.0-11)$ & 0.56 \\
\hline Renal arteries ${ }^{a}$ & 17 & $3.8 \pm 0.9(2.1-5.0)$ & 15 & $4.3 \pm 1.1(3.0-6.1)$ & 0.17 \\
\hline Femoral arteries & 10 & $4.1 \pm 0.8(2.9-5.0)$ & 10 & $4.0 \pm 0.6(3.5-5.4)$ & 0.92 \\
\hline Axillary arteries & 10 & $3.9 \pm 0.6(3.0-5.0)$ & 10 & $3.5 \pm 0.7(2.5-4.3)$ & 0.28 \\
\hline Renal veins & 15 & $6.1 \pm 1.8(3.5-9.6)$ & 16 & $5.5 \pm 1.9(3.7-11)$ & 0.19 \\
\hline Jugular veins & 9 & $2.9 \pm 0.8(2.1-4.2)$ & 8 & $2.8 \pm 0.5(2.0-3.4)$ & 0.76 \\
\hline Vascular bundles & 6 & $4.7 \pm 0.5(4.0-5.5)$ & 12 & $4.6 \pm 1.8(2.8-9.0)$ & 0.89 \\
\hline
\end{tabular}

${ }^{a}$ Cranial and caudal portions were often sealed separately, resulting in $>20$ renal arteries ( 10 animals $\times 2$ kidneys) 
Table 2 In situ vessel or vascular bundle diameters immediately before sealing (Primary experiment)

\begin{tabular}{|c|c|c|c|c|c|}
\hline \multirow[t]{2}{*}{ Vessel type } & \multicolumn{2}{|c|}{ thermoSEAL mode (TSM) } & \multicolumn{2}{|c|}{ BiClamp ${ }^{\oplus}$ mode (BCM) } & \multirow[t]{2}{*}{$p$ value } \\
\hline & No. & mean \pm STD (range) $[\mathrm{mm}]$ & No. & mean \pm STD (range) $[\mathrm{mm}]$ & \\
\hline All vessels & 50 & $4.5 \pm 1.5(2.1-9.6)$ & 49 & $4.4 \pm 1.4(2.2-9.0)$ & 0.75 \\
\hline Arteries & 25 & $3.7 \pm 0.8(2.1-5.9)$ & 23 & $4.0 \pm 1.1(2.9-6.8)$ & 0.79 \\
\hline Veins & 19 & $5.4 \pm 1.7(3.2-9.6)$ & 14 & $5.0 \pm 1.3(2.2-6.9)$ & 0.45 \\
\hline Vascular bundles & 6 & $4.7 \pm 0.5(4.0-5.5)$ & 12 & $4.6 \pm 1.8(2.8-9.0)$ & 0.89 \\
\hline
\end{tabular}

The same is true for relaparotomy after 21 days with even more advanced or fully completed healing.

\section{Intraoperative seal failure}

Intraoperative seal failures were rare (total: $8 / 196 \approx 4 \%$ ) and comparable between TSM and BCM $(2 / 98 \approx 2 \%$ vs. $6 / 98 \approx 6 \%, p=0.28$ ). Of these eight failures, two arteries and two veins could be resealed with a maximum of two further sealing activations, as allowed per protocol. Three further vessels were sutured: a renal artery and a splenic vein as resealing was not possible because the remaining vascular stump was too short to be grasped with the vessel sealer and a femoral artery since the other two sealing activations were unsuccessful. One vascular bundle was not resealed because the seal failure only occurred on the side adjacent to an explanted spleen.

\section{Sealing time}

The sealing time of all vessels was significantly shorter for TSM $(3.5 \pm 0.7 \mathrm{~s})$ compared to BCM $(7.3 \pm 1.3 \mathrm{~s}, p<$ $0.0001)$. The same is true for arteries, veins, renal arteries or vascular bundles $(p<0.0001$, Table 4$)$. The sealing time with the BCM did not correlate with vessel diameter, while with the TSM a significant positive correlation between these parameters with a slope of $0.22 \mathrm{~s} /$ mm was observed (Fig. 1).

\section{Thermal lateral spread (TL)}

Seventy-four of 97 ( $\approx 76 \%)$ sealed blood vessels (52 arteries, 22 veins) from the terminal experiments were used to measure TL. Twenty-three blood vessels $(\approx 24 \%)$ could not be assessed due to insufficient visibility of TL. This can be explained by the in vivo setting, which is associated with more blood on the specimens and possible rupture of the specimens. Overall, TL near the sealing sites (Table 5) was similar with TSM and BCM ( $p=$
0.61) with an approximate mean extent of $0.7 \mathrm{~mm}$. There was also no difference between the two modes regarding arteries $(p=0.96)$, veins $(p=0.28)$ or other anatomically specified vessel types $(p>0.05)$. A modeindependent comparison of the TL of the different blood vessel types also showed no significant differences ( $p=$ $0.65)$.

\section{Burst pressure (BP)}

The BP of 128 vascular stumps tested ex vivo was similar for TSM and BCM $(479 \pm 263 \mathrm{mmHg}$ vs. $469 \pm 313$ mmHg, $p=0.45$, Table 6 and Fig. 2a). These 128 stumps were taken from 90 transected vessels (TSM: 45, BCM: $45)$ corresponding to 180 vascular stumps. Since the sensitive tissue quality of some specimens did not allow a connection to the experimental BP test bench, 52 stumps $(\approx 29 \%)$ could not be used in this test (TSM: $21 \approx$ $23 \%$, BCM: $31 \approx 34 \%$ ). Based on the BP values, it was decided to analyse subgroups of veins smaller or larger than $5 \mathrm{~mm}$ in diameter. In addition, the arteries were divided into groups according to their anatomical origin. There was no difference between the modes concerning arteries $(p=0.18$, Fig. $2 \mathrm{~b})$, veins $(p=0.62)$, femoral arteries $(p=0.67)$, axillary arteries $(p=0.90)$, renal veins $(p=$ $0.20)$ and veins with a diameter smaller than $5 \mathrm{~mm}(p=$ $0.32)$ or larger than $5 \mathrm{~mm}(p=0.29)$. Renal arteries showed significantly higher BP values for the TSM $(p<$ 0.001 , Fig. 2c) and jugular veins showed significantly higher $\mathrm{BP}$ values for the BCM $(p<0.05)$. Regardless of the mode, the BP of axillary arteries was higher than that of the femoral arteries $(507 \pm 253 \mathrm{mmHg}$ vs. $371 \pm 179$ $\mathrm{mmHg}, p=0.01)$ and the BP of veins smaller than $5 \mathrm{~mm}$ was higher than that of veins larger than $5 \mathrm{~mm}(609 \pm$ $360 \mathrm{mmHg}$ vs. $182 \pm 71.6 \mathrm{mmHg}, p<0.0001)$. A comparison of the BPs of renal and jugular veins showed higher values for the jugular veins with both TSM and $\operatorname{BCM}(p<0.01)$.

Table 3 In situ vessel diameters immediately before sealing (Terminal experiment)

\begin{tabular}{|c|c|c|c|c|c|}
\hline \multirow{2}{*}{$\begin{array}{l}\text { Vessel } \\
\text { type }\end{array}$} & \multicolumn{2}{|c|}{ thermoSEAL mode (TSM) } & \multicolumn{2}{|c|}{ BiClamp ${ }^{\oplus}$ mode (BCM) } & \multirow[t]{2}{*}{$p$ value } \\
\hline & No. & mean \pm STD (range) $[\mathrm{mm}]$ & No. & $\overline{\text { mean } \pm \text { STD (range) }[\mathrm{mm}]}$ & \\
\hline All vessels & 48 & $4.3 \pm 1.4(2.1-8.1)$ & 49 & $4.2 \pm 1.5(2.0-11)$ & 0.79 \\
\hline Arteries & 31 & $4.2 \pm 0.8(2.9-6.0)$ & 33 & $4.1 \pm 0.8(2.5-6.1)$ & 0.97 \\
\hline Veins & 17 & $4.5 \pm 2.1(2.1-8.1)$ & 16 & $4.4 \pm 2.3(2.0-11)$ & 0.95 \\
\hline
\end{tabular}


Table 4 Sealing time (Primary and terminal experiment)

\begin{tabular}{|c|c|c|c|c|c|}
\hline \multirow[t]{2}{*}{ Vessel type } & \multicolumn{2}{|c|}{ thermoSEAL mode (TSM) } & \multicolumn{2}{|c|}{ BiClamp ${ }^{\oplus}$ mode $(\mathrm{BCM})$} & \multirow[t]{2}{*}{$p$ value } \\
\hline & No. & mean \pm STD (range) $[\mathrm{mm}]$ & No. & mean \pm STD (range) $[\mathrm{mm}]$ & \\
\hline All vessels & 97 & $3.5 \pm 0.69(2.5-5.9)$ & 88 & $7.3 \pm 1.3(3.5-11)$ & $<0.0001$ \\
\hline Arteries & 55 & $3.4 \pm 0.65(2.5-5.9)$ & 51 & $7.4 \pm 1.4(3.5-11)$ & $<0.0001$ \\
\hline Veins & 36 & $3.6 \pm 0.78(2.5-5.2)$ & 27 & $7.4 \pm 1.4(4.7-10)$ & $<0.0001$ \\
\hline Renal arteries & 17 & $3.5 \pm 0.45(2.8-4.4)$ & 15 & $7.4 \pm 1.4(5.1-9.8)$ & $<0.0001$ \\
\hline Vascular bundles & 6 & $3.7 \pm 0.54(3.0-4.4)$ & 10 & $6.9 \pm 0.87(5.7-8.7)$ & $<0.0001$ \\
\hline
\end{tabular}

$6 \%(11 / 196)$ of the vessels seals with unintended multiple activations could not be evaluated

\section{Tissue sticking, tissue charring and cut quality}

Tissue sticking to the vessel sealer was relatively uncommon and similar for TSM and BCM (13/98 $\approx 13 \%$ vs. 19/ $98 \approx 19 \%, p=0.33)$. The occurrence of sealing events without sticking (rating 0) did not differ between TSM and $\mathrm{BCM}(85 / 98 \approx 87 \%$ vs. $79 / 98 \approx 81 \%, p=0.33)$, which also applied to the other ratings (Table 7$)$. Tissue charring was classified as non-existent regardless of the mode, i. e. $100 \%$ (98/98) of the vessels were rated ' 0 ' in both cases. The cut quality was very similar for TSM and BCM $(1.03 \pm 0.16, n=39$ vs. $1.03 \pm 0.16, n=39)$, i.e. $97 \%(38 / 39)$ of the seals were cut in the first attempt and only $3 \%(1 / 39)$ were cut in the second attempt regardless of the mode.

\section{Histology}

Seven thermally sealed carotid arteries were examined at microscopic level ( 4 x BCM, 3 x TSM). All samples except one (BCM\#3) showed fusion of the arterial walls with complete occlusion of the arterial lumen. The arterial walls directly adjacent to the sealing site showed transmural thermal alterations

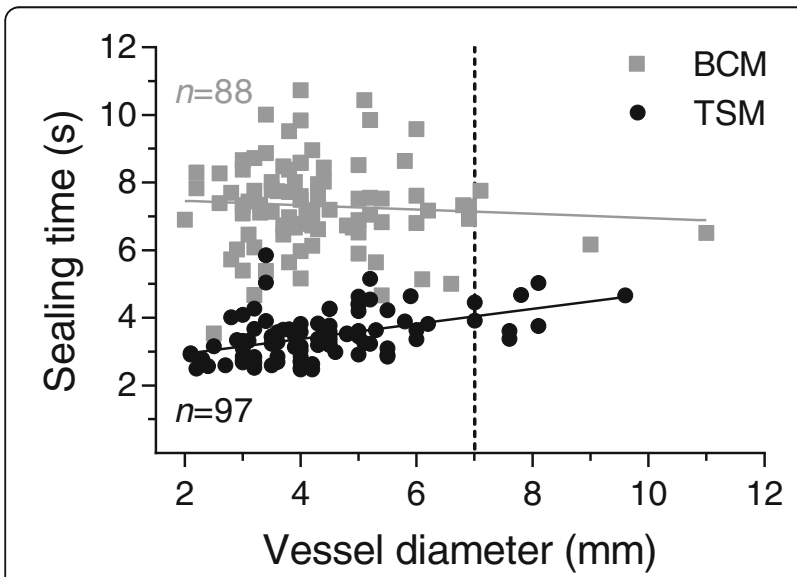

Fig. 1 Sealing time vs. vessel diameter of sealed arteries, veins and vascular bundles for TSM (black circles) and BCM (grey squares). TSM showed a significant positive correlation $\left(p<0.0001, R^{2}=0.21\right)$, whereas BCM did not $\left(p=0.57, R^{2}=0.005\right)$. The vertical dashed line shows the maximum diameter approved with the BiCision ${ }^{\circledR}$ vessel sealer $(7 \mathrm{~mm})$. This figure was presented on a poster [25] with strong denaturation in the outer third, affecting adventitia and media. The transition from normal arterial structures to arterial wall affected by surgery was characterized by a broad transmural zone of intra- and extracellular vacuolisation (Fig. 3). This zone was observed equally in both groups, as well as minor thrombus formation in the arterial lumen adjacent to the sealing site (Fig. 4). Most vessels $(6 / 7 \approx$ $86 \%)$ showed a complete invagination of the interrupted media into the arterial lumen, which is typical for electrothermal vessel sealing (Table 8).

\section{Discussion}

Both TSM and BCM showed a low intraoperative seal failure rate $(\approx 2 \%$ vs. $\approx 6 \%)$. Regardless of mode, seal failures in arteries, veins and vascular bundles were similarly rare $(\approx 4 \%, \approx 5 \%$ and $\approx 6 \%, p=0.65)$. Clinically, this is a remarkable result. Richter et al. also observed no differences between arteries and veins with regard to seal failure [11]. It is known that seal failure rates increase with vessel diameter [26]. Although vessels with a large diameter range $(2.0-11.0 \mathrm{~mm})$ were sealed, this correlation could not be confirmed, probably due to the low seal failure rate, few vessels with a diameter above $7 \mathrm{~mm}(n=9)$ and the resulting lack of statistical power. Therefore, no difference in vessel diameter was observed for failed seals compared to successful seals $(4.7 \pm 1.2$ $\mathrm{mm}, n=8$ vs. $4.3 \pm 1.4 \mathrm{~mm}, n=188, p=0.34)$. All ten animals survived 5 or 21 days and on second look the sealing sites and surrounding tissue showed no signs of complications or evidence of bleeding. The optimal long-term seal quality and the excellent intraoperative seal failure rate show that the primary aim was fulfilled. The validity of the results is confirmed by the fact that the composition of the vessels and their diameters were very similar for TSM and BCM (Tables 1, 2 and 3).

The mean sealing time of the TSM was $3.5 \mathrm{~s}$ and shorter than that of the BCM $(p<0.0001)$. This shortening of the sealing time with TSM was indicated by earlier in vivo animal tests [7] and was confirmed here with a higher number of samples. It is 
Table 5 Thermal lateral spread $(T L)$

\begin{tabular}{|c|c|c|c|c|c|}
\hline \multirow[t]{2}{*}{ Vessel type } & \multicolumn{2}{|c|}{ thermoSEAL mode (TSM) } & \multicolumn{2}{|c|}{ BiClamp ${ }^{\oplus}$ mode (BCM) } & \multirow[t]{2}{*}{$p$ value } \\
\hline & No. & mean \pm STD (range) $[\mathrm{mm}]$ & No. & mean \pm STD (range) $[\mathrm{mm}]$ & \\
\hline All vessels & 40 & $0.68 \pm 0.32(0-1.4)$ & 34 & $0.72 \pm 0.41(0-1.4)$ & 0.61 \\
\hline Arteries & 27 & $0.67 \pm 0.31(0-1.2)$ & 25 & $0.68 \pm 0.45(0-1.4)$ & 0.96 \\
\hline Veins & 13 & $0.69 \pm 0.34(0.2-1.4)$ & 9 & $0.85 \pm 0.27(0.4-1.4)$ & 0.28 \\
\hline Renal arteries & 7 & $0.74 \pm 0.13(0.6-1.0)$ & 6 & $0.70 \pm 0.48(0.2-1.4)$ & 0.81 \\
\hline Femoral arteries & 10 & $0.64 \pm 0.43(0-1.2)$ & 8 & $0.49 \pm 0.40(0-1.0)$ & 0.46 \\
\hline Axillary arteries & 9 & $0.64 \pm 0.28(0.2-1.0)$ & 10 & $0.85 \pm 0.46(0.1-1.4)$ & 0.26 \\
\hline Renal veins & 5 & $0.65 \pm 0.28(0.3-1.0)$ & 4 & $1.0 \pm 0.26(0.7-1.4)$ & 0.19 \\
\hline Jugular veins & 8 & $0.72 \pm 0.39(0.2-1.4)$ & 5 & $0.72 \pm 0.24(0.4-1.0)$ & 0.99 \\
\hline
\end{tabular}

$24 \%$ (23/97) of the vessels could not be evaluated (see Results section TL)

remarkable that a significant positive correlation between sealing time and vessel diameter was observed for the TSM, reflecting an appropriate function of the closed loop electrical regulation, taking into account the change in tissue impedance during the sealing process. In addition, the sealing time of the TSM varied only slightly and less than that of the BCM (S.D. $=0.69$ s vs. S.D. $=1.3 \mathrm{~s}, p<0.0001$ ). Low variance in sealing time should have a positive effect on handling and the feeling of safety. Compared to other vessel sealers used in recent in vivo animal studies $[11,13,27,28]$, the sealing time of the TSM is relatively short (Fig. 5). Short sealing times are beneficial and lead to a shorter total surgery time, especially in laparoscopy. The aim of shortening the sealing time while maintaining clinical success rates was achieved by further developing the ESU's regulation.

The TL was very similar with TSM and $\mathrm{BCM}(p=$ 0.61 , Table 5). The extent of TL is competitive (Fig. 6) with other vessel sealers $[20,29]$. The TL was independent of the vessel type $(p=0.65)$. This is in line with data from others $[14,20]$ and a previous report from us [28]. It was reported that TL increases with vessel diameter [20], but this correlation was not confirmed ( $\left.p=0.49, R^{2}=0.01\right)$. Moreover, a significant reduction in TL with TSM compared to BCM as demonstrated by ex vivo bench tests [7] could not be confirmed here with a higher number of samples. Since this study showed no difference in TL and the ex vivo tests showed less TL with TSM, these results taken together suggest that TSM could cause even less, but definitely not more TL compared to BCM. The aim of reducing TL at consistent clinical success rates may have been achieved even though the standard with $\mathrm{BCM}$ is high.

$\mathrm{BP}$ values were similar with TSM and BCM (Table 6). Bench testing with renal arteries showed a BP of $774 \pm 190 \mathrm{mmHg}$ for the TSM, which was similar in this study (Fig. 2c, $745 \pm 264 \mathrm{mmHg}$ ). Arterial BPs

Table 6 Ex vivo burst pressure (BP)

\begin{tabular}{|c|c|c|c|c|c|}
\hline \multirow[t]{2}{*}{ Vessel type } & \multicolumn{2}{|c|}{ thermoSEAL mode (TSM) } & \multicolumn{2}{|c|}{ BiClamp $^{\circledast}$ mode $(B C M)$} & \multirow[t]{2}{*}{$p$ value } \\
\hline & No. & mean \pm STD (range) [mm] & No. & mean \pm STD (range) [mm] & \\
\hline All vessels & 69 & $479 \pm 263(57-1116)$ & 59 & $469 \pm 313(72-1430)$ & 0.45 \\
\hline Arteries & 49 & $499 \pm 255(57-1102)$ & 46 & $435 \pm 255(72-1090)$ & 0.18 \\
\hline Veins & 20 & $431 \pm 282(60-1116)$ & 13 & $587 \pm 457(171-1430)$ & 0.62 \\
\hline Renal arteries & 12 & $745 \pm 264(57-1102)$ & 10 & $286 \pm 166(72-606)$ & $<0.001$ \\
\hline Femoral arteries & 16 & $333 \pm 113(170-620)$ & 15 & $411 \pm 227(115-876)$ & 0.67 \\
\hline Axillary arteries & 19 & $509 \pm 221(267-1050)$ & 19 & $504 \pm 287(80-1090)$ & 0.90 \\
\hline Renal veins & 6 & $163 \pm 72.9(60-266)$ & 6 & $210 \pm 41.6(171-273)$ & 0.20 \\
\hline Jugular veins & 14 & $545 \pm 259(300-1116)$ & 7 & $910 \pm 390(360-1430)$ & 0.019 \\
\hline Veins < $5 \mathrm{~mm}$ & 15 & $522 \pm 265(198-1116)$ & 9 & $743 \pm 460(188-1430)$ & 0.32 \\
\hline Veins $>5$ mm & 5 & $156 \pm 79.2(60-266)$ & 4 & $215 \pm 51.8(171-273)$ & 0.29 \\
\hline
\end{tabular}

The $n$ given represents the number of vascular stumps used for BP testing. $29 \%$ (52/180) of the vascular stumps could not be evaluated (TSM: $21 \approx 23 \%$, BCM: $31 \approx 34 \%$ ) (see Results section BP) 


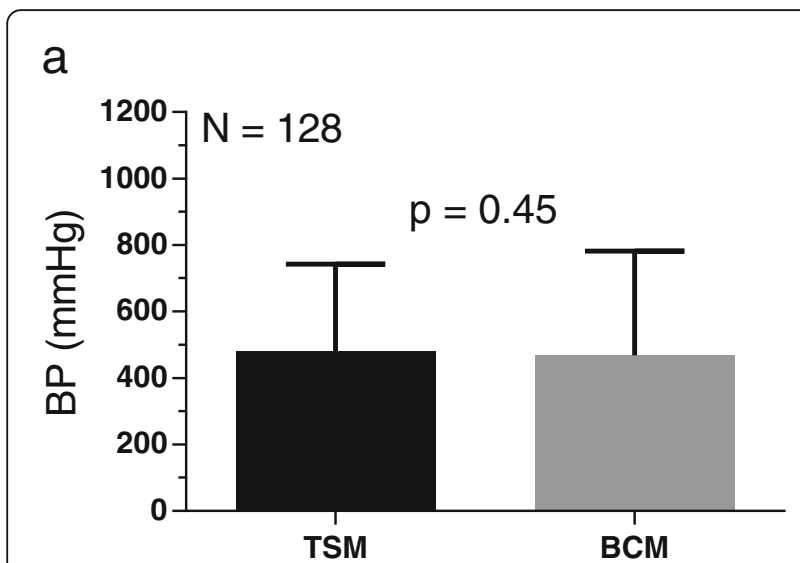

b

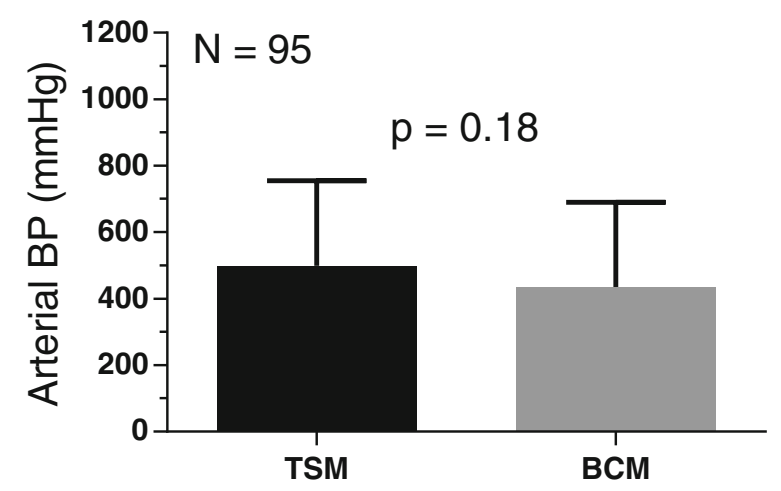

C

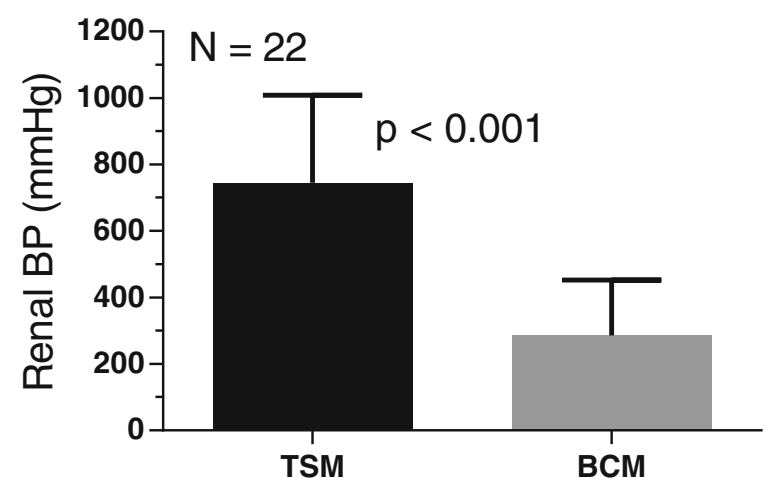

Fig. 2 BP for TSM (black) and BCM (grey) with the BiCision ${ }^{\circledR}$ device: a Arteries and veins. $N=128$. b Arteries. $N=95$. c Renal arteries. $N=$ 22. Figure b was presented on a poster [25]

show a dependence on anatomical origin so that renal arteries can withstand the highest pressure, followed by axillary arteries, and the lowest BPs were measured for femoral arteries. Sindram et al. also showed decreasing BPs for renal, carotid, iliac and femoral arteries, suggesting that collagen content is the most important determinant of BP [17]. The vessel diameter, which is also a predictor for
BP, was not significantly different for these artery groups, as was the case for the arteries in this study. Latimer et al. also showed that collagen content is a good predictor for BP of human blood vessels with a diameter of $<5 \mathrm{~mm}$ using LigaSure Atlas, whereas it is less important for vessels with a diameter of $>5 \mathrm{~mm}$ [30]. This suggests that the variance in arterial BP can mainly be explained by collagen content, while the vessel diameter seems to be negligible up to at least $5 \mathrm{~mm}$. A comparison of our BP values with other animal tests $[9,18,27,31,32]$ using LigaSure or EnSeal is shown in Fig. 7. A statistical comparison of the values is not recommended as there are considerable differences in vessel diameter and composition. However, it can be concluded that an appropriate number of vessels were tested in this study and that the arterial BP values of the TSM are competitive. The mean venous BP of the TSM was $492 \pm 363 \mathrm{mmHg}$. This comparatively high value can be explained by the different types of veins and their diameters. If only renal veins typically $>5 \mathrm{~mm}$ in diameter were considered (Table 1), the mean BP was $163 \pm 72.9 \mathrm{mmHg}$. This value is consistent with a study by Landmann et al., who reported a mean $\mathrm{BP}$ of $233 \mathrm{mmHg}$ for 11 porcine renal veins [9]. In contrast, we found that the jugular veins with a mean diameter of merely $2.9 \pm 0.8$ $\mathrm{mm}$ (Table 1) had BP values greater than 500 $\mathrm{mmHg}$, which is untypically high for veins and higher than, for example, the values obtained in 2011 with EnSeal $(262 \pm 51 \mathrm{mmHg}, n=14) \quad$ [33]. However, a number of studies report high BP values for certain veins: Dunay et al. obtained high BP values for jugular veins using EnSeal (lowest value $425 \mathrm{mmHg}$ ) [18]. Overhaus et al. reported a mean BP of $425 \pm 74 \mathrm{mmHg}$ for small porcine veins (diameter 1-5 mm) using EnSeal, which was even higher than in arteries of similar diameter [34]. Kennedy et al. reported a mean $\mathrm{BP}$ of $378 \pm 211 \mathrm{mmHg}$ for porcine renal, splenic, ovarian and uterine veins (diameter $1-7 \mathrm{~mm}, n=13$ ) using a prototypic bipolar vessel sealer [2]. Furthermore, Noble et al. obtained

Table 7 Rating of tissue sticking to the vessel sealer

\begin{tabular}{|c|c|c|c|c|c|}
\hline \multirow{2}{*}{$\begin{array}{l}\text { Rating } \\
\text { level }\end{array}$} & \multicolumn{2}{|c|}{ thermoSEAL mode (TSM) } & \multicolumn{2}{|c|}{ BiClamp $^{\circledast}$ mode (BCM) } & \multirow[t]{2}{*}{$p$ value } \\
\hline & No. & Percentage [\%] & No. & Percentage [\%] & \\
\hline Rating 0 & $85 / 98$ & 87 & $79 / 98$ & 81 & 0.33 \\
\hline Rating 1 & 9/98 & 9 & 9/98 & 9 & 1.00 \\
\hline Rating 2 & $3 / 98$ & 3 & $7 / 98$ & 7 & 0.33 \\
\hline Rating 3 & $1 / 98$ & 1 & $3 / 98$ & 3 & 0.62 \\
\hline
\end{tabular}

Ratings: $0=$ no sticking, $1=$ sticking, but easy to remove the device, $2=$ sticking and difficult to remove the device, $3=$ sticking and difficult to remove the device and seal damaged 


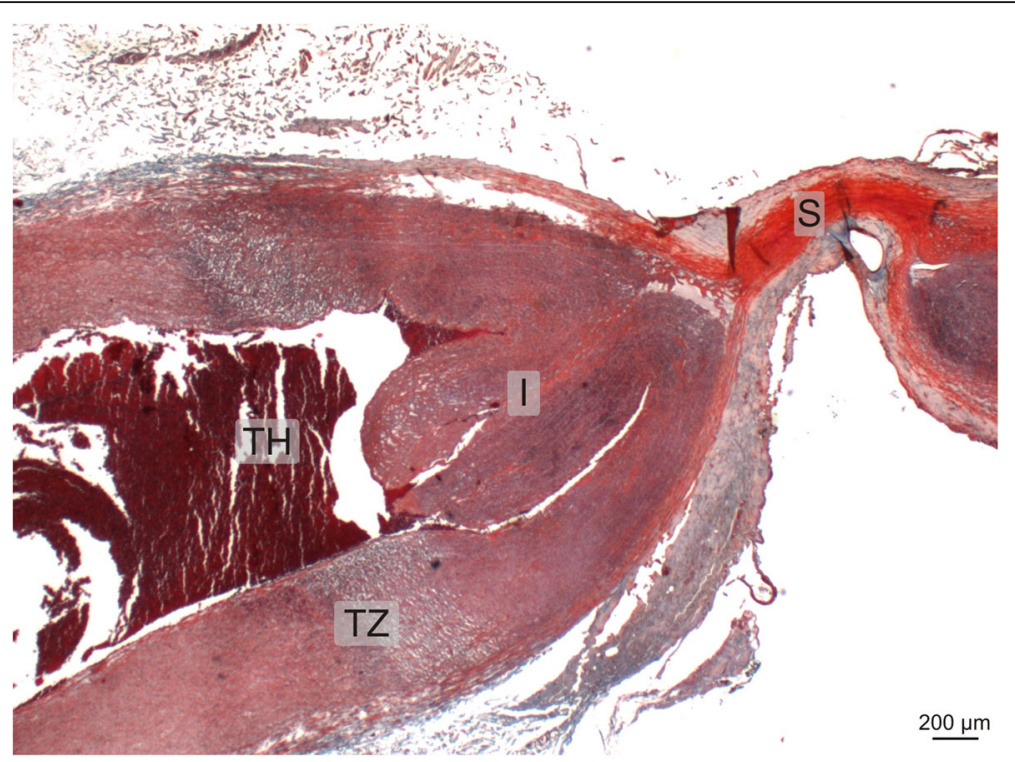

Fig. 3 Histological section of a typical thermally sealed artery stained with MTC: The sealing site (S, upper right) shows the bright red colour of denatured collagen. The invagination of the media (I) and a thrombus (TH) can be seen. The transition zone (TZ) between denatured and unaffected arterial structures is characterised by a broad transmural zone of intra- and extracellular vacuolisation

BP values above $1000 \mathrm{mmHg}$ for ex vivo human veins with a diameter of $\sim 1 \mathrm{~mm}$ using LigaSure and other devices [35]. When interpreting experimental $\mathrm{BP}$ results, it should be borne in mind that these are usually far above the physiological blood pressure values. In summary, it can be said that arterial and venous BP values measured for the two modes are competitive with and in agreement with other measurements presented in the current literature.
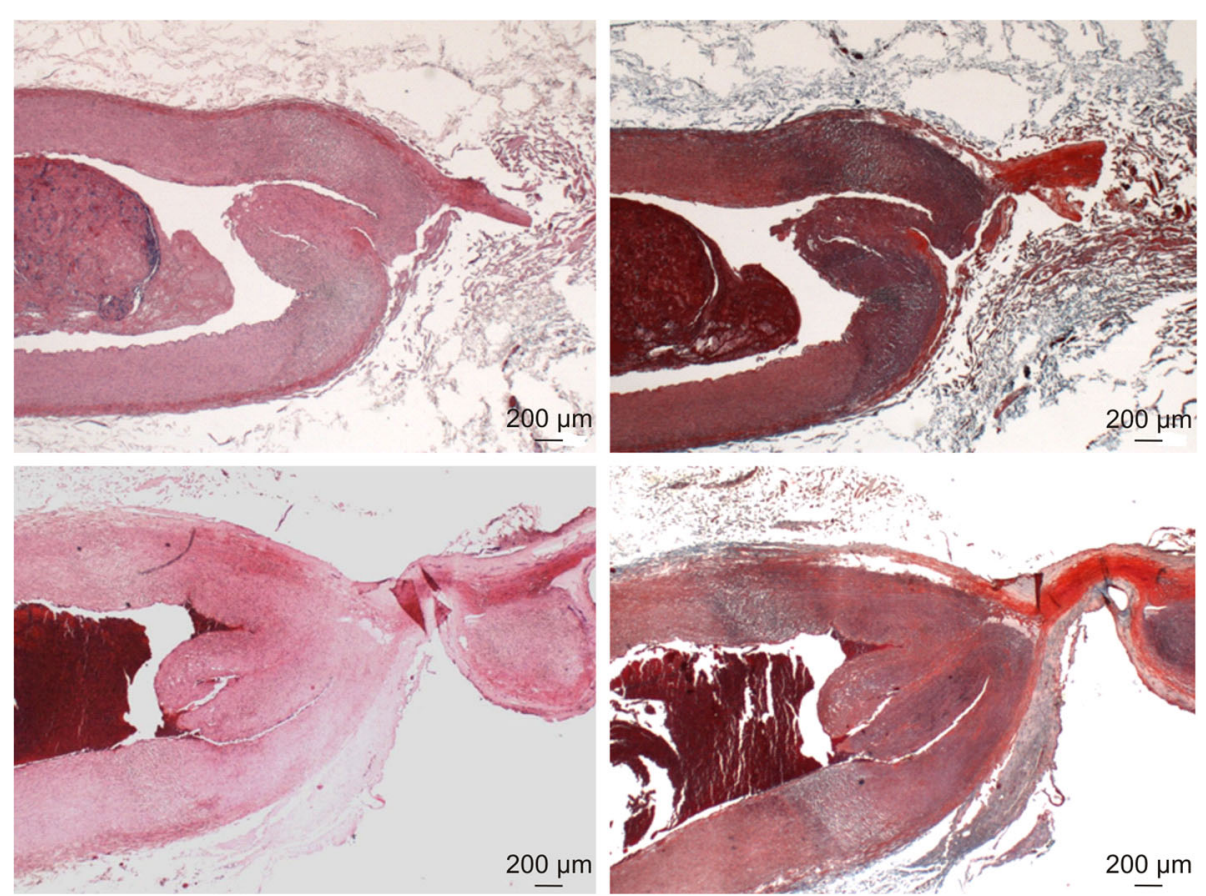

Fig. 4 Histological comparison between two thermally sealed arteries (BCM top, TSM bottom, left HE stain, right MTC stain): Both samples show similar alterations caused by the sealing process: strong thermal alterations with denaturation of protein components in the vessel wall, of the adventitia and media next to the sealing sites and a transition zone between unaffected and affected media 
Table 8 Histological properties of sealed carotid arteries

\begin{tabular}{|c|c|c|c|c|c|c|c|}
\hline \multirow[t]{2}{*}{ Property } & \multicolumn{7}{|l|}{ Sample \# } \\
\hline & BCM\#1 & $\mathrm{BCM} \# 2$ & $\mathrm{BCM} \# 3$ & $\mathrm{BCM} \# 4$ & TSM\#1 & TSM\#2 & TSM\#3 \\
\hline Occlusion of arterial lumen & Yes & Yes & $\mathrm{No}^{\mathrm{a}}$ & Yes & Yes & Yes & Yes \\
\hline Transition zone & Broad & Broad & Small & Broad & Broad & Broad & Broad \\
\hline Thrombus formation & Yes & No & Yes, strong & No & Yes & Yes & Yes \\
\hline Invagination of the media & Complete & Complete & Incomplete & Complete & Complete & Complete & Complet \\
\hline
\end{tabular}

${ }^{a}$ The arterial lumen reopened, probably because of the mechanical excision of the specimen from the animal

Electrosurgical devices are generally known to occasionally stick to tissue and tend to accumulate layers of contamination [28, 31]. This may be clinically relevant, particularly in laparoscopy, as forced movements to release the device from the coagulated and transected tissue may result in seal failure. Regardless of the mode, tissue sticking to the device was not common in this study ( $\approx 13 \%$ vs. $\approx 19 \%, p=0.33$, Table 7 ). Therefore, the novel TSM is neither a significant improvement nor deterioration in tissue sticking. Tissue charring was considered non-existent in both modes. Regarding the cut quality, $97 \%$ of the seals were cut in the first attempt and only $3 \%$ were cut in the second attempt with both modes. This corresponds to the previously obtained data, which show a very high cut quality of BiCision ${ }^{\circ}$ [28]. Since the evaluation of tissue sticking, tissue

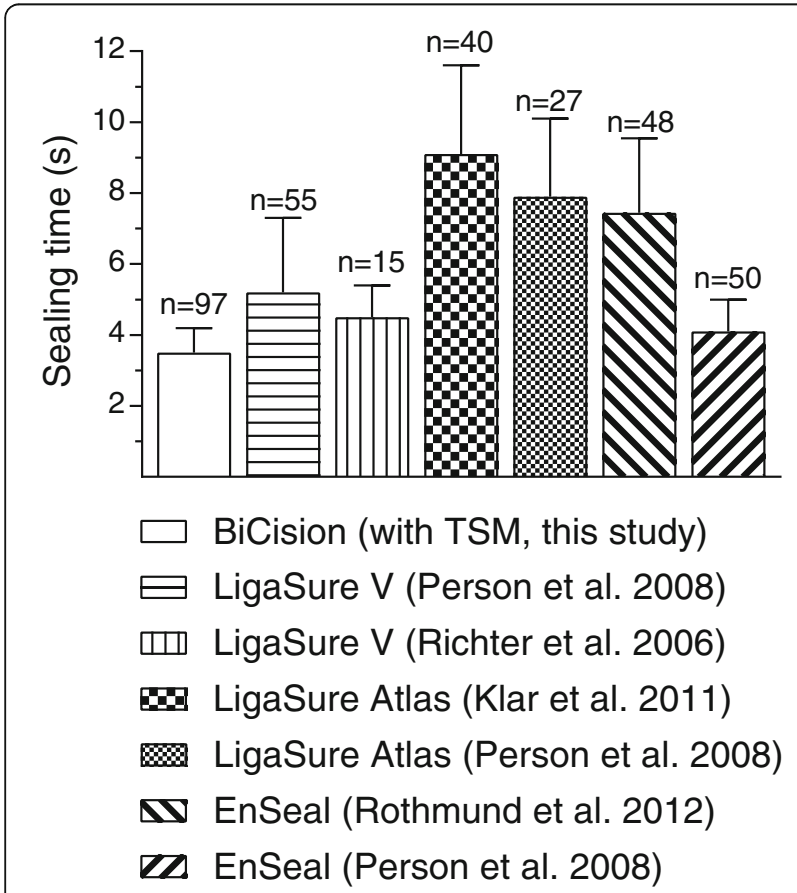

Fig. 5 Sealing times of different electrosurgical vessel sealers. Data is included from this study (no fill pattern) and other in vivo animal studies (Klar et al. [27], Person et al. [13], Richter et al. [11], Rothmund et al. [28]) charring and cut quality is subjective and userdependent, the interpretation of the result of these aspects remains a methodological limitation.

The histological evaluation of the successfully sealed vessels showed no differences between the two modes. The distribution of thermal alterations and the invagination of the media typical for electrothermally sealed vessels were identical. One caveat is the small number of specimens evaluated. Nevertheless, the histological results agree with the macroscopic evaluation of TL, which also showed no differences between TSM and BCM.

\section{Conclusions}

Apart from technical specifications of an electrosurgical device, especially the geometry of the device jaws which are in direct contact with the target tissue, the ESU's

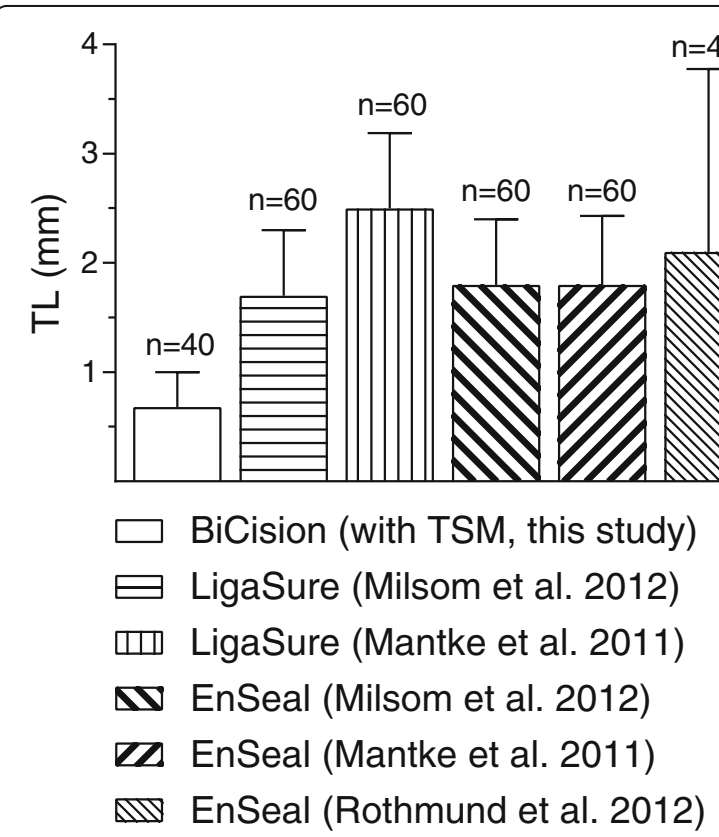

Fig. $6 \mathrm{TL}$ of different vessel sealers. Data is included from this study (no fill pattern) and other in vivo (Milsom et al. [20], Rothmund et al. [28]) and ex vivo (Mantke et al. [29]) animal studies 


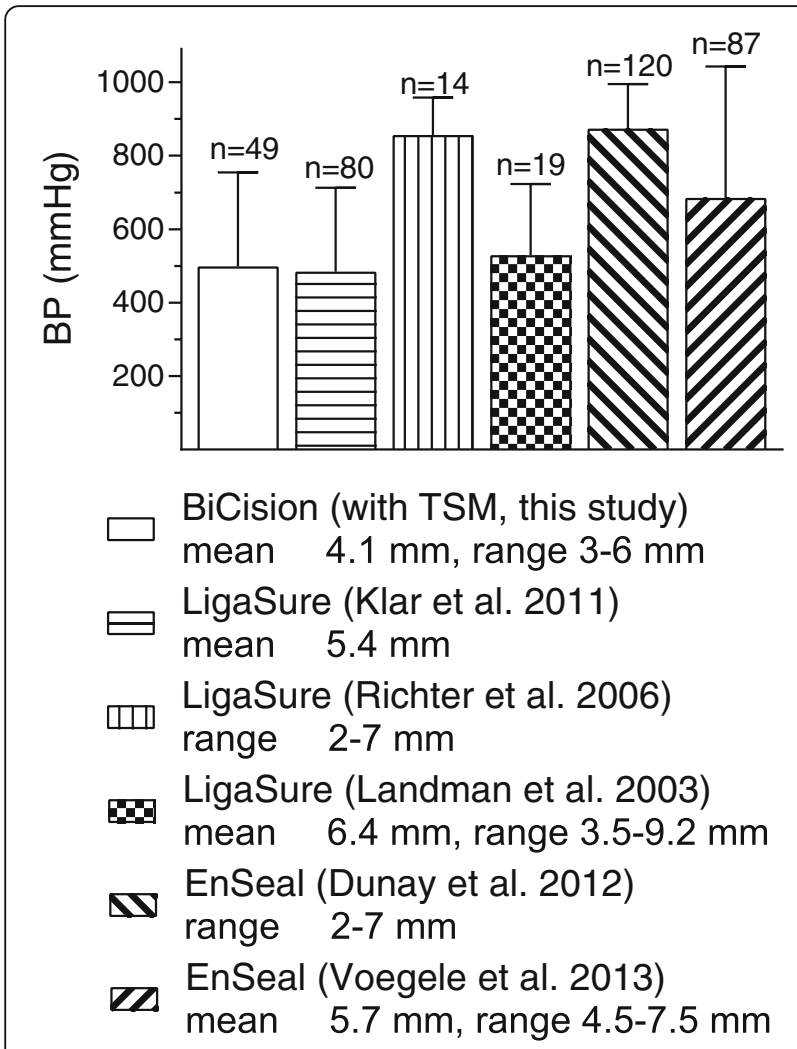

Fig. 7 Arterial BP of this study (no fill pattern) in comparison to other in vivo (Klar et al. [27], Richter et al. [31], Landman et al. [9], Dunay et al. [18] [includes 30 veins and 30 arteries]) and ex vivo (Voegele et al. [32]) animal studies. Mean and/or range of the arterial vessel diameters in the legend. $n$ is the number of vascular stumps

algorithm plays an important role for fast, safe and successful vessel sealing. The further development of userfriendly intelligent modes is therefore just as important as the design of ergonomic instruments. In this context, our study presents the novel TSM, which seals blood vessels twice as fast as the $\mathrm{BCM}$, while providing excellent tissue effect and clinical success rates.

\section{Abbreviations}

BCM: BiClamp ${ }^{\oplus}$ mode; BP: Burst pressure; ESU: Electrosurgical unit; HE: Haematoxylin and eosin; MTC: Masson's trichrome; PSR: Picro Sirius Red; TL: Thermal lateral spread; TSM: ThermoSEAL mode

\section{Acknowledgements}

We thank A. Stolz, C. Fahrner and T. O. Greiner for their excellent veterinarian and technical assistance.

\section{Authors' contributions}

UB and MDE designed the study. UB was responsible for the data acquisition. Surgery was carried out by BK, CT and SKr. The analysis and interpretation of the data was performed by BK, MSche and UB. Histological evaluation was performed by MScha and DN. The manuscript was written by BK and UB. The manuscript was critically revised by SB, SKo and MDE. All authors have read and approved the final manuscript.

\section{Funding}

Erbe Elektromedizin $\mathrm{GmbH}$ is the sponsor of this study. The sponsor is interested in evaluating the safety and performance of the TSM, which is a product of the sponsor. Accordingly, the study was designed, analysed and written to reach this aim. The authors declare that the interpretation of the data was not influenced by the sponsor's funding.

\section{Availability of data and materials}

The data that support the findings of this study are available from Erbe Elektromedizin $\mathrm{GmbH}$, but restrictions apply to the availability of these data, which were used under license for the current study, and so are not publicly available. Data are however available from the authors upon reasonable request and with permission of Erbe Elektromedizin $\mathrm{GmbH}$.

\section{Ethics approval and consent to participate}

This animal study met the formal and ethical standards of the authorities and was approved by the institutional review board for animal experiments, Regierungspraesidium Tuebingen, Germany (approval number F2/15) in compliance with the Animals Scientific Procedures Act 1986. The animals were obtained from a German GbR (Gesellschaft buergerlichen Rechts) in Bingen. The company name may not be published.

\section{Consent for publication}

Not applicable.

\section{Competing interests}

U.B., M.D.E. and D.N. are employees of Erbe Elektromedizin GmbH. B.K., C.T., S.Kr., M.Sche., M.Scha., S.Ko. and S.B. have no competing interests or financial ties to disclose.

\section{Author details}

${ }^{1}$ University Hospital Tuebingen, Tuebingen, Germany. ${ }^{2}$ Helios Klinikum Pforzheim, Pforzheim, Germany. ${ }^{3}$ Erbe Elektromedizin GmbH,

Waldhoernlestrasse 17, 72072 Tuebingen, Germany.

Received: 12 April 2019 Accepted: 15 October 2019

Published online: 05 November 2019

\section{References}

1. Harold KL, Pollinger H, Matthews BD, Kercher KW, Sing RF, Heniford BT. Comparison of ultrasonic energy, bipolar thermal energy, and vascular clips for the hemostasis of small-, medium-, and large-sized arteries. Surg Endosc. 2003;17:1228-30. https://doi.org/10.1007/s00464-002-8833-7.

2. Kennedy JS, Stranahan PL, Taylor KD, Chandler JG. High-burst-strength, feedback-controlled bipolar vessel sealing. Surg Endosc. 1998;12:876-8.

3. Bibi S, Alblawi S, Velchuru V, Thripuraneni G, Quinteros F, Coralic J, et al. Sealing of vessels larger than 7 millimeters using Enseal in porcine aorta. JSLS. 2014. https://doi.org/10.4293/JSLS.2014.00182.

4. Wallwiener C, Wallwiener M, Neunhoeffer E, Menger M, Isaacson K, Zubke W. Intelligent, impedance-regulated, pulsed coagulation in a porcine renal artery model. Fertil Steril. 2007;88:206-11. https://doi.org/10.1016/j.fertnstert. 2006.11.204.

5. Oussoultzoglou E, Panaro F, Rosso E, Zeca I, Bachellier P, Pessaux P, Jaeck D. Use of BiClamp decreased the severity of hypocalcemia after total thyroidectomy compared with LigaSure: a prospective study. World I Surg. 2008;32:1968-73. https://doi.org/10.1007/s00268-008-9671-0.

6. Wallwiener CW, Rajab TK, Zubke W, Isaacson KB, Enderle M, Schäller D, Wallwiener M. Thermal conduction, compression, and electrical current--an evaluation of major parameters of electrosurgical vessel sealing in a porcine in vitro model. J Minim Invasive Gynecol. 2008;15:605-10. https://doi.org/10. 1016/j.jmig.2008.05.003.

7. Thiel K, Linzenbold W, Enderle MD, Nold B, Königsrainer A, Schenk M, Thiel C. Evaluation of a novel electrosurgical sealing mode in an ex vivo and in vivo porcine model. Surg Endosc. 2018;32:1456-63. https://doi.org/10. 1007/s00464-017-5832-2.

8. Spivak H, Richardson WS, Hunter JG. The use of bipolar cautery, laparosonic coagulating shears, and vascular clips for hemostasis of small and mediumsized vessels. Surg Endosc. 1998;12:183-5.

9. Landman J, Kerbl K, Rehman J, Andreoni C, Humphrey PA, Collyer W, et al. Evaluation of a vessel sealing system, bipolar electrosurgery, harmonic scalpel, titanium clips, endoscopic gastrointestinal anastomosis vascular staples and sutures for arterial and venous ligation in a porcine model. J. Urol. 2003;169:697-700. https://doi.org/10.1097/01.ju.0000045160.87700.32. 
10. Campbell PA, Cresswell AB, Frank TG, Cuschieri A. Real-time thermography during energized vessel sealing and dissection. Surg Endosc. 2003;17:16405. https://doi.org/10.1007/s00464-002-8781-2.

11. Richter S, Kollmar O, Schilling MK, Pistorius GA, Menger MD. Efficacy and quality of vessel sealing: comparison of a reusable with a disposable device and effects of clamp surface geometry and structure. Surg Endosc. 2006;20: 890-4. https://doi.org/10.1007/s00464-005-0380-6.

12. Hruby GW, Marruffo FC, Durak E, Collins SM, Pierorazio P, Humphrey PA, et al. Evaluation of surgical energy devices for vessel sealing and peripheral energy spread in a porcine model. J Urol. 2007;178:2689-93. https://doi.org/ 10.1016/j.juro.2007.07.121.

13. Person B, Vivas DA, Ruiz D, Talcott M, Coad JE, Wexner SD. Comparison of four energy-based vascular sealing and cutting instruments: a porcine model. Surg Endosc. 2008;22:534-8. https://doi.org/10.1007/s00464-007-9619-8.

14. Pietrow PK, Weizer AZ, L'Esperance JO, Auge BK, Silverstein A, Cummings T, et al. PlasmaKinetic bipolar vessel sealing: burst pressures and thermal spread in an animal model. J Endourol. 2005;19:107-10. https://doi.org/10. 1089/end.2005.19.107.

15. Santa-Cruz RW, Auge BK, Lallas CD, Preminger GM, Polascik TJ. Use of bipolar laparoscopic forceps to occlude and transect the retroperitoneal vasculature: a porcine model. J Endourol. 2003;17:181-5. https://doi.org/10. 1089/089277903321618761.

16. Phillips CK, Hruby GW, Durak E, Lehman DS, Humphrey PA, Mansukhani MM, Landman J. Tissue response to surgical energy devices. Urology. 2008; 71:744-8. https://doi.org/10.1016/j.urology.2007.11.035.

17. Sindram D, Martin K, Meadows JP, Prabhu AS, Heath JJ, McKillop IH, lannitti DA. Collagen-elastin ratio predicts burst pressure of arterial seals created using a bipolar vessel sealing device in a porcine model. Surg Endosc. 2011; 25:2604-12. https://doi.org/10.1007/s00464-011-1606-4.

18. Dunay MP, Jakab C, Németh T. Evaluation of EnSeal ${ }^{\oplus}$, an adaptive bipolar electrosurgical tissue-sealing device. Acta Vet Hung. 2012;60:27-40. https:// doi.org/10.1556/AVet.2012.003.

19. Seehofer D, Mogl M, Boas-Knoop S, Unger J, Schirmeier A, Chopra S, Eurich D. Safety and efficacy of new integrated bipolar and ultrasonic scissors compared to conventional laparoscopic 5-mm sealing and cutting instruments. Surg Endosc. 2012;26:2541-9. https://doi.org/10.1007/s00464-012-2229-0.

20. Milsom J, Trencheva K, Monette S, Pavoor R, Shukla P, Ma J, Sonoda T. Evaluation of the safety, efficacy, and versatility of a new surgical energy device (THUNDERBEAT) in comparison with harmonic ACE, LigaSure V, and EnSeal devices in a porcine model. J Laparoendosc Adv Surg Tech A. 2012; 22:378-86. https://doi.org/10.1089/lap.2011.0420.

21. Berdah SV, Hoff C, Poornoroozy PH, Razek P, van Nieuwenhove Y. Postoperative efficacy and safety of vessel sealing: an experimental study on carotid arteries of the pig. Surg Endosc. 2012;26:2388-93. https://doi.org/10. 1007/s00464-012-2177-8

22. Diamantis T, Kontos M, Arvelakis A, Syroukis S, Koronarchis D, Papalois A, et al. Comparison of monopolar electrocoagulation, bipolar electrocoagulation, Ultracision, and Ligasure. Surg Today. 2006;36:908-13. https://doi.org/10.1007/s00595-006-3254-1.

23. Tanaka R, Gitelis M, Meiselman D, Abar B, Zapf M, Carbray J, et al. Evaluation of vessel sealing performance among ultrasonic devices in a porcine model. Surg Innov. 2015;22:338-43. https://doi.org/10.1177/1553350615579730.

24. Chen J, Manwaring PK, Scott RR, Manwaring KH, Glasgow RE. Ferromagnetic heating for vessel sealing and division: utility and comparative study to ultrasonic and bipolar technologies. Surg Innov. 2015;22:329-37. https://doi. org/10.1177/1553350615580648.

25. Krämer B, Rothmund R, Schenk M, Kruck S, Mischinger J, Ederer M, et al. Bipolare Thermofusion von biologischem Gewebe: ThermoSEAL als neuer Mode für die Gefäßversiegelung. Geburtshilfe Frauenheilkd. 2016. https:// doi.org/10.1055/s-0036-1593066.

26. Newcomb WL, Hope WW, Schmelzer TM, Heath JJ, Norton HJ, Lincourt AE, et al. Comparison of blood vessel sealing among new electrosurgical and ultrasonic devices. Surg Endosc. 2009;23:90-6. https://doi.org/10.1007/s00464-008-9932-x.

27. Klar M, Haberstroh J, Timme S, Fritzsch G, Gitsch G, Denschlag D. Comparison of a reusable with a disposable vessel-sealing device in a sheep model: efficacy and costs. Fertil Steril. 2011;95:795-8. https://doi.org/10. 1016/j.fertnstert.2010.09.014.

28. Rothmund R, Kraemer B, Neis F, Brucker S, Wallwiener M, Reda A, et al Efficacy and safety of the novel electrosurgical vessel sealing and cutting instrument BiCision ${ }^{\oplus}$. Surg Endosc. 2012;26:3334-43. https://doi.org/10.1007/ s00464-012-2337-x.
29. Mantke R, Halangk W, Habermann A, Peters B, Konrad S, Guenther M, Lippert H. Efficacy and safety of 5-mm-diameter bipolar and ultrasonic shears for cutting carotid arteries of the hybrid pig. Surg Endosc. 2011;25: 577-85. https://doi.org/10.1007/s00464-010-1224-6.

30. Latimer CA, Nelson M, Moore CM, Martin KE. Effect of collagen and elastin content on the burst pressure of human blood vessel seals formed with a bipolar tissue sealing system. J Surg Res. 2014;186:73-80. https://doi.org/10. 1016/j.jss.2013.08.003.

31. Richter S, Kollmar O, Neunhoeffer E, Schilling MK, Menger MD, Pistorius G. Differential response of arteries and veins to bipolar vessel sealing: evaluation of a novel reusable device. J Laparoendosc Adv Surg Tech A. 2006;16:149-55. https://doi.org/10.1089/lap.2006.16.149.

32. Voegele AC, Korvick DL, Gutierrez M, Clymer JW, Amaral JF. Perpendicular blood vessel seals are stronger than those made at an angle. J Laparoendosc Adv Surg Tech A. 2013;23:669-72. https:/doi.org/10.1089/lap.2013.0028.

33. Szyrach MN, Paschenda P, Afify M, Schäller D, Tolba RH. Evaluation of the novel bipolar vessel sealing and cutting device BiCision ${ }^{\circledast}$ in a porcine model. Minim Invasive Ther Allied Technol. 2012;21:402-7. https://doi.org/ 10.3109/13645706.2012.661373.

34. Overhaus M, Schaefer N, Walgenbach K, Hirner A, Szyrach MN, Tolba RH. Efficiency and safety of bipolar vessel and tissue sealing in visceral surgery. Minim Invasive Ther Allied Technol. 2012;21:396-401. https://doi.org/10. 3109/13645706.2011.651145.

35. Noble EJ, Smart NJ, Challand C, Sleigh K, Oriolowo A, Hosie KB. Experimental comparison of mesenteric vessel sealing and thermal damage between one bipolar and two ultrasonic shears devices. Br J Surg. 2011;98:797-800. https://doi.org/10.1002/bjs.7433.

\section{Publisher's Note}

Springer Nature remains neutral with regard to jurisdictional claims in published maps and institutional affiliations.
Ready to submit your research? Choose BMC and benefit from:

- fast, convenient online submission

- thorough peer review by experienced researchers in your field

- rapid publication on acceptance

- support for research data, including large and complex data types

- gold Open Access which fosters wider collaboration and increased citations

- maximum visibility for your research: over $100 \mathrm{M}$ website views per year

At BMC, research is always in progress.

Learn more biomedcentral.com/submissions 